\title{
Landing Dynamic and Key Parameter Estimations of a Landing Mecha- nism to Asteroid with Soft Surface
}

\author{
Zhijun Zhao*, JingDong Zhao** and Hong Liu*** \\ State Key Laboratory of Robotics and System, Harbin Institute of Technology, Harbin, China
}

\begin{abstract}
It is of great significance to utilize a landing mechanism to explore an asteroid. A landing mechanism named ALISE (Asteroid Landing and In Situ Exploring) for asteroid with soft surface is presented. The landing dynamic in the first turning stage, which represents the landing performance of the landing mechanism, is built by a Lagrange equation. Three key parameters can be found influencing the landing performance: the retro-rocket thrust $\mathrm{T}$, damping element damping $c_{1}$, and cardan element damping $c_{2}$. In this paper, the retro-rocket thrust $\mathrm{T}$ is solved with considering that the landing mechanism has no overturning in extreme landing conditions. The damping element damping $c_{1}$ is solved by a simplified dynamic model. After solving the parameters $\mathrm{T}$ and $c_{1}$, the cardan element damping $c_{2}$ is calculated using the landing dynamic model, which is built by Lagrange equation. The validities of these three key parameters are tested by simulation. The results show a stable landing, when landing with the three estimated parameters $\mathrm{T}, c_{1}$, and $c_{2}$. Therefore, the landing dynamic model and methods to estimate key parameters are reasonable, and are useful for guiding the design of the landing mechanism.
\end{abstract}

Key words: asteroid landing mechanism, landing dynamic, landing performance, damping

\section{Introduction}

There are enormous asteroids formed at the beginning of the solar system. Most of them are rich in minerals, and some of them are dangerous to the Earth $[1,2]$. Thus, exploring the asteroids is of great significance, with the purpose of obtaining great economic effectiveness, and protecting the Earth. Landing on an asteroid is a great step towards exploring these asteroids, and its merits include: 1) learning about asteroids in situ; 2) changing dangerous asteroid orbits; 3) using asteroids as platforms to observe other celestial bodies; 4) using asteroids as carrying devices; 5) establishing communication stations on asteroids, and 6) capturing asteroids with minerals and bringing them back to earth $[3,4]$. However, these merits can only be carried out after a lander is able to land safely on an asteroid. Landing safely or not is represented by the landing performance, and the landing performance is usually evaluated by both the overloading acceleration and stability time, which are included in the landing dynamic model. Thus, it is of great significance to estimate the key parameters that will induce a good landing performance, by building a landing dynamic model. Besides, the values of these key parameters can guide the design of the landing mechanism.

Presently, most of the landing dynamic models are designed for lunar landing mechanisms, but are not suited to small body landing mechanisms, because of different landing environments, with different landing strategies [511]. The Europe Space Agency (ESA), National Aeronautics and Space Administration (NASA), and Japan Aerospace Exploration Agency (JAXA) have developed small body landing mechanisms, but the landing dynamic model is rarely used to evaluate the landing performance, and to guide the design of the landing mechanism [12-16]. They just evaluate the landing performance by simulation with the given value of the parameters, but don't show how these values are educed [17].

In this paper, an Asteroid Landing and In Situ Exploring ("ALISE") landing mechanism for asteroid with soft surface
This is an Open Access article distributed under the terms of the Creative Commons Attribution Non-Commercial License (http://creativecommons.org/licenses/by$\mathrm{nc} / 3.0 /$ which permits unrestricted non-commercial use, distribution, and reproduction in any medium, provided the original work is properly cited. (cc) * Ph. D Student

** Associate Professor, Corresponding author: zhaojingdong@hit.edu.cn *** Professor 
is presented. The landing dynamic model in the first turning stage is built by Lagrange equation. It can be found that there are three key parameters (retro-rocket thrust $\mathrm{T}$, damping element damping $c_{1}$ and cardan element damping $c_{2}$ ) that will influence the landing performance. Thus, the values of these three parameters must be estimated, to achieve excellent landing performance. The paper firstly estimates the value of $\mathrm{T}$, by considering that the retro-rocket will prevent the landing mechanism from overturning, by counteracting the turning energy. Secondly, the value of $c_{2}$ is estimated by a simplified dynamic model. Thirdly, after defining the values of $\mathrm{T}$ and $c_{1}$, the value of $c_{2}$ is calculated by the landing dynamic model, with the objective function of having the shortest stability time, and the constraint condition that the overloading acceleration is less than $10 \mathrm{~g}$. Lastly, the validities of these three values are tested, by simulating the landing performance in Adams software.

\section{The ALISE landing mechanism}

The ALISE landing mechanism aims at asteroids with soft surface(especially C type asteroid), which are softer than other asteroids, because of containing organic materials and amino acids [18, 19], and the design is inspired by the Rosetta lander and the ST4/Champollion lander [20-22]. The ALISE landing mechanism includes a three-leg landing gear, and an anchoring system that is designed to avoid the flying away of the lander under low gravity. The landing gear contains landing foot, landing legs, cardan element, damping element, and equipment base. The damping element is realized by electromagnetic damping, which is a new technology in deep space exploration. This damping mode has the merits of high efficiency, easy control, adjustable damping, and so on, and has been used in the Rosetta landing mechanism [20]. The anchoring system contains anchoring element, propulsion element, rewinding element, and cushion element. The schematics and the performance parameters are shown

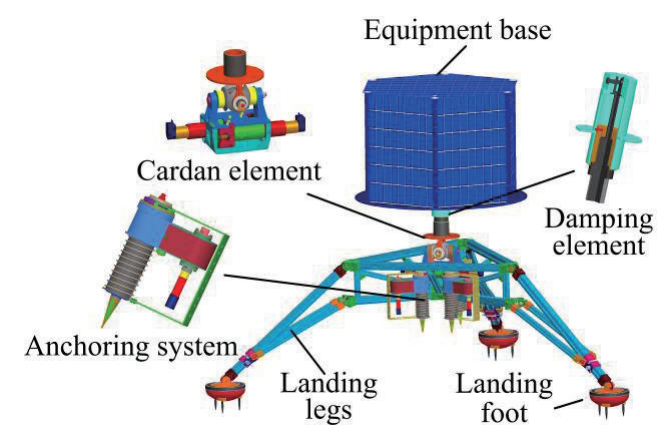

Fig. 1. Schematic of the landing mechanism
Table 1. Mechanical and landing performance parameters

\begin{tabular}{cc}
\hline Items & Values \\
\hline Landing gear mass & $45 \mathrm{~kg}$ \\
Payload mass & $\leq 55 \mathrm{~kg}$ \\
Anchoring system mass & $1 \mathrm{~kg}$ \\
Horizontal velocity & $\leq 0.5 \mathrm{~m} / \mathrm{s}$ \\
Vertical velocity & $\leq 1.5 \mathrm{~m} / \mathrm{s}$ \\
Landing slope & $\leq 30^{\circ}$ \\
Medium tensile strength & $0.5 \mathrm{MPa} \leq \tau \leq 5 \mathrm{MPa}$ \\
Anchoring time & $\leq 5 \mathrm{~s}$ \\
Anchoring force & $\geq 100 \mathrm{~N}$ \\
Penetration velocity & $50 \mathrm{~m} / \mathrm{s} \sim 100 \mathrm{~m} / \mathrm{s}$ \\
Rewinding force & About $20 \mathrm{~N}$ \\
Thread length & $2 \mathrm{~m}$ \\
\hline
\end{tabular}

separately in Fig. 1 and Table 1. Besides, the retro-rocket is fixed on the upper surface of the equipment base, to supply thrust towards the landing slope, to prevent the rebound of the landing mechanism, when landing. There is no sign of the retro-rocket in the schematics, because it is a part of the control system, but not a part of the mechanical structure.

There are awls beneath the landing feet to preventing sliding, and contact switches inside the landing feet, to generate landing signals. The cardan element has the functions of both absorbing the horizontal impact when landing, and adjusting the attitude of the equipment base after landing, while the damping element is just used to absorb the vertical impact. The anchoring element, which connects to the rewinding element via a thread, will be pushed rapidly into the asteroid by the propulsion element. At the time of penetration of the anchoring element, the rewinding element will quickly rewind the thread. When the thread is instantaneously tense, the cushion element, which is composed of a compression spring, will absorb the impact, to protect the rewinding motor. The retro-rocket will be activated at the time of landing, and supply a constant force lasting about 5 seconds toward the equipment base, to prevent the landing mechanism from rebounding.

\section{Landing dynamic model}

The surface of the asteroid with soft surface is soft. When landing, the awls will penetrate the asteroid some depth, to prevent sliding of the landing mechanism, and the retrorocket would be activated, to counteract the rebound of the 
landing mechanism. Then, the landing mechanism will turn clockwise or counterclockwise around the feet's anchoring points. The interaction between the awls and the surface is three-dimensional and very complicated, and few reasonable models can express this interaction accurately. Furthermore, the dynamic parameters in the first turning stage are enough to express the landing performance. Thus, the paper only develops the landing dynamic of the first turning stage. There are two-dimensional and three-dimensional landing dynamic models. But considering that the two-dimensional model is successfully adopted by the lunar lander, and that it is simpler than the three-dimensional model, a twodimensional landing dynamic is built for the ALISE landing mechanism.

Some hypotheses are made in building the landing dynamic model: 1) the gravity on the asteroid is of the order of magnitude about $10^{-4} \mathrm{~m} / \mathrm{s}^{2}$, therefore the gravity is ignored; 2) the friction between the landing feet and landing legs is ignored; 3) The stiffness of the landing gear is far greater than that of the damping element vertically, and of the cardan element horizontally. So the flexibility of the landing gear is ignored; 4) the impulse acting on the landing mechanism when shooting the anchoring system is ignored; 5) the overturning of the landing mechanism is over, before the anchoring system tenses the thread.

As shown in the right part of Fig. 2, the landing mechanism will turn around the point $\mathrm{O}$ when landing. The whole system has three degrees of freedom: rotational DOF of $\mathrm{m}_{1}$; rotational DOF of $\mathrm{m}_{2}$; and translational DOF of $\mathrm{m}_{2}$. The Lagrange equation is introduced, to build the landing dynamic model. The kinetic energy $T$, potential energy $V$, and Rayleigh's Dissipation Function $\psi_{q}$ are shown in equations (1) and (2) respectively. The meanings and values of the parameters in equations are shown in Fig. 2 and Table 2.

$$
\begin{aligned}
T= & \frac{1}{2}\left[\mathrm{~J}_{\mathrm{lc}}+\left(\mathrm{m}_{1}+\mathrm{m}_{2}\right) \mathrm{L}_{1}^{2}\right] \dot{\varphi}_{1}^{2}+\frac{1}{2} \mathrm{~J}_{2 c} \dot{\varphi}_{2}^{2}+\mathrm{m}_{2} \mathrm{~L}_{1} \dot{\varphi}_{1} \dot{s} \sin \left(\varphi_{2}-\varphi_{1}-\alpha\right)+\mathrm{m}_{2} \mathrm{~L}_{1} s \dot{\varphi} \dot{\varphi}_{1} \cos \left(\varphi_{2}-\varphi_{1}-\alpha\right) \\
& +\frac{1}{2} \mathrm{~m}_{2}\left(\dot{s}^{2}+s^{2} \dot{\varphi}_{2}^{2}\right)
\end{aligned}
$$

$$
V=0, \quad \psi_{q}=\frac{1}{2} c_{1} \dot{s}^{2}+\frac{1}{2} c_{2}\left(\dot{\varphi}_{2}-\dot{\varphi}_{1}\right)^{2}
$$

Then, the Lagrange dynamic equations are deduced, as shown in equations (3), (4) and (5).

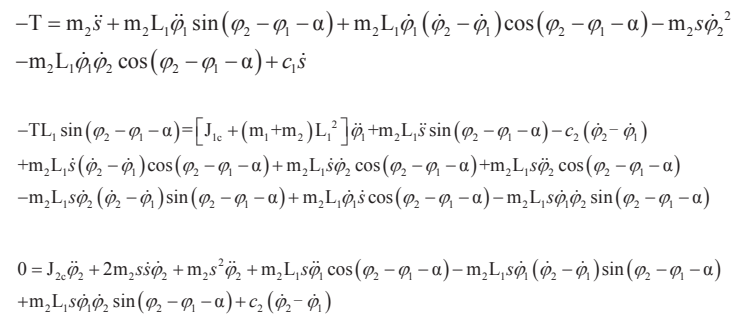

The parameters $s, \varphi_{1}, \varphi_{2}, \dot{s}, \dot{\varphi}_{1}, \dot{\varphi}_{2}, \ddot{s}, \ddot{\varphi}_{1}$ and $\ddot{\varphi}_{2}$ of landing dynamic characteristics can be solved by equations (3), (4) and (5) with the initial values. However, in a complicated landing impact, the initial values are difficult, or impossible to solve accurately - they can only be estimated. A schematic of the impact is shown in the left part of Fig. 2. Firstly, the impacting force acting on $\mathrm{ml}$ at point $\mathrm{O}$ is far larger than the other external force, thus the impulse of $m_{2}$ acting on $m_{1}$ can be ignored. So the angular momentum of $\mathrm{ml}$ around $\mathrm{O}$ is conservational. Secondly, ignoring the retro-rocket thrust $\mathrm{T}$, the angular momentum of the system composed of $\mathrm{m}_{1}$ and $\mathrm{m}_{2}$ is conservational. Thirdly, there is a damping element between the $m_{1}$ and $m_{2}$ vertically, therefore the vertical velocity of the $m_{2}$ changes continuously. Therefore the following equation (6) can be deduced. Meanings and values of the parameters in equation (6) are shown in Table 2.

$$
\left\{\begin{array}{l}
0=\left(\mathrm{J}_{1 \mathrm{c}}+\mathrm{m}_{1} \mathrm{~L}_{1}^{2}\right) \omega_{1}-\left(\mathrm{m}_{1} V_{x} \mathrm{~b}_{1}-\mathrm{m}_{1} V_{y} \mathrm{a}\right) \\
0=\left(\mathrm{J}_{1 \mathrm{c}}+\mathrm{m}_{1} \mathrm{~L}_{1}^{2}\right) \omega_{1}+\mathrm{J}_{2 c}\left(\omega_{1}+\omega_{2}\right)+\mathrm{m}_{2}\left(\omega_{1} \mathrm{~b}_{1}+\omega_{2} \mathrm{~S}_{2}\right) \mathrm{b}_{2}-\left(\mathrm{m}_{1} V_{x} \mathrm{~b}_{1}-\mathrm{m}_{1} V_{y} \mathrm{a}+\mathrm{m}_{2} V_{x} \mathrm{~b}_{2}\right) \\
V_{y}=-\omega_{1} \mathrm{a}+V_{21 y}
\end{array}\right.
$$

where, $\omega_{1}, \omega_{2}$ and $V_{21 y}$ can be calculated from equations (6). Thus, the initial values to solve the equations (3), (4) and (5) are obtained, as shown in equation (7).

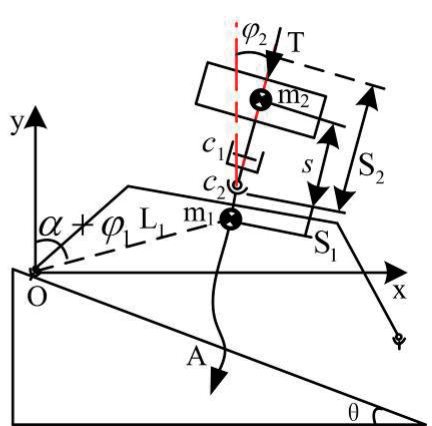

Fig. 2. 2 Schematics of the landing mechanism impact and turning 


$$
\left\{\begin{array}{l}
s(t=0)=\mathrm{S}_{2} \\
\varphi_{1}(t=0)=0 \\
\varphi_{2}(t=0)=0 \\
\dot{s}(t=0)=V_{21 \mathrm{y}} \\
\dot{\varphi}_{1}(t=0)=\omega_{1} \\
\dot{\varphi}_{2}(t=0)=\omega_{1}+\omega_{2}
\end{array}\right.
$$

\section{Estimations of the key parameters $T, c_{1}$ and $\mathrm{C}_{2}$}

From the landing dynamic model, as shown in equations (3), (4) and (5), it can be found that the landing performance parameters $s, \varphi_{1}, \varphi_{2}, \dot{s}, \dot{\varphi}_{1}, \dot{\varphi}_{2}, \ddot{s}, \ddot{\varphi}_{1}, \ddot{\varphi}_{2}$ are determined by $T, c_{1}$ and $c_{2}$. So to have a superior landing performance, it is necessary to determine the proper values of $T, c_{1}$, and $c_{2}$.

\subsection{Estimation of retro-rocket thrust $T$}

The retro-rocket supplies constant force $\mathrm{T}$ towards the upper surface of the equipment base, to prevent the landing mechanism from rebounding and overturning. In order to find the safe thrust, it is assumed that the landing mechanism is a rigid body, and its initial kinetic energy is counteracted entirely by the retro-rocket thrust. There are counterclockwise overturning, and clockwise overturning. They need different values of thrust, to prevent overturning. Thus, it is necessary to estimate the thrust separately for the two types of overturning, and then the largest value is taken as the retro-rocket thrust value.

\subsubsection{Counterclockwise overturning}

When landing with the initial velocity $V_{x}=-0.5 \mathrm{~m} / \mathrm{s}$ and $V_{y}=0 \mathrm{~m} / \mathrm{s}$ in 2-1 mode, the landing mechanism will turn counterclockwise, and have the most possibility to overturn counterclockwise. This schematic is shown in the left part of the Fig. 3. The meanings and values of the parameters in the schematic are shown in Table 3.

The landing mechanism turns around the $\mathrm{O}$ point counterclockwise after impact, and the initial overturn angular velocity $\omega_{L}$ can be estimated from the angular momentum conservation of $\mathrm{m}$ around $\mathrm{O}$. Thus, the following equation is obtained:

\begin{tabular}{|c|c|c|}
\hline Parameters & Meaning & Value \\
\hline $\mathrm{m}_{1}$ & mass beneath cardan element & $22 \mathrm{~kg}$ \\
\hline $\mathrm{m}_{2}$ & mass above cardan element & $78 \mathrm{~kg}$ \\
\hline $\mathrm{J}_{1 \mathrm{c}}$ & $\mathrm{m}_{1}$ inertia & $3.54 \mathrm{~kg} \cdot \mathrm{m}^{2}$ \\
\hline $\mathrm{J}_{2 \mathrm{c}}$ & $\mathrm{m}_{2}$ inertia & $4.79 \mathrm{~kg} \cdot \mathrm{m}^{2}$ \\
\hline $\mathrm{L}_{1}$ & length between $\mathrm{m}_{1}$ and $\mathrm{O}$ & $1.001 \mathrm{~m}$ \\
\hline $\mathrm{S}_{1}$ & length between $\mathrm{m}_{1}$ and $c_{2}$ & $0.163 \mathrm{~m}$ \\
\hline $\mathrm{S}_{2}$ & initial length from $\mathrm{m}_{2}$ to $c_{2}$ & $0.344 \mathrm{~m}$ \\
\hline $\mathrm{a}$ & $\mathrm{m}_{1}$ abscissa length & $0.927 \mathrm{~m}$ \\
\hline$b_{1}$ & $\mathrm{~m}_{1}$ ordinate length & $0.388 \mathrm{~m}$ \\
\hline$b_{2}$ & $\mathrm{~m}_{2}$ ordinate length & $0.895 \mathrm{~m}$ \\
\hline$\alpha$ & initial angle between y axis and $\mathrm{Om}_{1}$ & $67.3^{\circ}$ \\
\hline$\theta$ & landing slope angle & $0 \sim 30^{\circ}$ \\
\hline$V_{\mathrm{x}}$ & horizontal landing velocity & $-0.5 \sim 0.5(\mathrm{~m} / \mathrm{s})$ \\
\hline$V_{\mathrm{y}}$ & vertical landing velocity & $-1.5 \sim 0(\mathrm{~m} / \mathrm{s})$ \\
\hline $\mathrm{T}$ & retro-rocket thrust & variable \\
\hline$c_{1}$ & damping element damping & variable \\
\hline$c_{2}$ & cardan element damping & variable \\
\hline$s$ & $\mathrm{~m}_{2}$ translation relative to $\mathrm{m}_{1}$ & related to $c_{1}, c_{2}, \mathrm{~T}$ \\
\hline$\varphi_{1}$ & $\mathrm{~m}_{1}$ rotation angle & related to $c_{1}, c_{2}, \mathrm{~T}$ \\
\hline$\varphi_{2}$ & $\mathrm{~m}_{2}$ rotation angle & related to $c_{1}, c_{2}, \mathrm{~T}$ \\
\hline$\omega_{1}$ & $\mathrm{~m}_{1}$ initial angular velocity & related to $V_{\mathrm{x}}, V_{\mathrm{y}}$ \\
\hline$\omega_{2}$ & $\mathrm{~m}_{2}$ initial angular velocity & related to $V_{\mathrm{x}}, V_{\mathrm{y}}$ \\
\hline$V_{21 \mathrm{y}}$ & $\mathrm{m}_{2}$ initial vertical velocity relative to $\mathrm{m}_{1}$ & related to $V_{\mathrm{x}}, V_{\mathrm{y}}$ \\
\hline
\end{tabular}

$$
-\mathrm{m} V_{x} \mathrm{~b}=\left[\mathrm{J}_{\mathrm{c}}+\mathrm{m}\left(\mathrm{a}^{2}+\mathrm{b}^{2}\right)\right] \omega_{L}
$$

The solution of equation (8) is:

Table 2. 2 Meanings and values of the parameters 


$$
\omega_{L}=\frac{-\mathrm{m} V_{x} \mathrm{~b}}{\mathrm{~J}_{\mathrm{c}}+\mathrm{m}\left(\mathrm{a}^{\prime 2}+\mathrm{b}^{2}\right)}=0.41 \mathrm{rad} / \mathrm{s}
$$

The largest allowable turning range of the landing mechanism without overturning is from $\mathrm{P}_{1}$ to $\mathrm{P}_{2}$. So the initial kinetic energy of the landing mechanism after impact should be counteracted totally by the retro-rocket thrust $\mathrm{T}_{1}$ during the angle $\angle \mathrm{P}_{1} \mathrm{OP}_{2}$, which equals $\pi / 2$. Therefore, the following equation is obtained:

$$
\frac{1}{2}\left[\mathrm{~J}_{\mathrm{c}}+\mathrm{m}\left(\mathrm{a}^{\prime 2}+\mathrm{b}^{2}\right)\right] \omega_{L}^{2}=\mathrm{T}_{1} \mathrm{a}^{\prime} \frac{\pi}{2}
$$

Obtaining:

$$
\mathrm{T}_{1}=\frac{\left[\mathrm{J}_{\mathrm{c}}+\mathrm{m}\left(\mathrm{a}^{\left.\left.\mathrm{a}^{2}+\mathrm{b}^{2}\right)\right] \omega_{L}^{2}}\right.\right.}{\pi \mathrm{a}^{\prime}}=11.04 \mathrm{~N}
$$

where, $T_{1}$ is the retro-rocket thrust preventing the landing mechanism from counterclockwise overturning.

\subsubsection{Clockwise overturning}

When landing with the initial velocity $V_{x}=0.5 \mathrm{~m} / \mathrm{s}$ and $V_{y}=-1.5 \mathrm{~m} / \mathrm{s}$ in $1-2$ mode, the landing mechanism will turn clockwise, and have the most possibility to overturn clockwise. This schematic is shown in the right part of Fig. 3. The meanings and values of the parameters in the schematic are shown in Table 2 and Table 3.

The landing mechanism turns around the $\mathrm{O}$ point clockwise after impact, and the initial turning angular velocity $\omega_{R 1}$ can be estimated from the angular momentum conservation of $\mathrm{m}$ around $\mathrm{O}$. Thus, the following equation is obtained:

$$
\mathrm{m} V_{x} \mathrm{~b}-\mathrm{m} V_{y} \mathrm{a}=\left[\mathrm{J}_{\mathrm{c}}+\mathrm{m}\left(\mathrm{a}^{2}+\mathrm{b}^{2}\right)\right] \omega_{R 1}
$$

Obtaining:

$$
\omega_{R 1}=\frac{\mathrm{m} V_{x} \mathrm{~b}-\mathrm{m} V_{y} \mathrm{a}}{\mathrm{J}_{\mathrm{c}}+\mathrm{m}\left(\mathrm{a}^{2}+\mathrm{b}^{2}\right)}=1.11 \mathrm{rad} / \mathrm{s}
$$

When the landing mechanism turns to the $\mathrm{P}_{2}$ position with the retro-rocket thrust $\mathrm{T}_{2}$, the angular velocity $\omega_{R 2}$ can be calculated by the energy conversion.

$$
\omega_{R 2}=\sqrt{\frac{\left[\mathrm{J}_{\mathrm{c}}+\mathrm{m}\left(\mathrm{a}^{2}+\mathrm{b}^{2}\right)\right] \omega_{R 1}{ }^{2}+2 \mathrm{~T}_{2} \mathrm{a} \theta}{\mathrm{J}_{\mathrm{c}}+\mathrm{m}\left(\mathrm{a}^{2}+\mathrm{b}^{2}\right)}}
$$

The tangential velocity of $\mathrm{m}$ in the $\mathrm{P}_{2}$ position is:

$$
V_{12}=\omega_{R 2} \sqrt{\mathrm{a}^{2}+\mathrm{b}^{2}}
$$

Then the landing mechanism will turn continuously around point $\mathrm{B}$. It is assumed that the recovery coefficient $e$ equals 0.6 between the landing mechanism and the landing surface ( $e$ equals 0.5 between wood and wood; $e$ equals 0.56 between steel and steel). Thus, the rebound velocity $V_{23}$ can be expressed as:

$$
V_{23}=e V_{12} \cos \beta
$$

Then the initial angular velocity $\omega_{R 3}$ around the point B is obtained:

$$
\omega_{R 3}=\frac{V_{23}}{\left|\mathrm{P}_{2} \mathrm{~B}\right|}=\frac{V_{23}}{\sqrt{\mathrm{a}^{\prime 2}+\mathrm{b}^{2}}}
$$

The largest allowable turning range of the landing mechanism, without overturning, is from $\mathrm{P}_{2}$ to $\mathrm{P}_{3}$. So the kinetic energy of the landing mechanism after $\mathrm{P}_{2}$ position should be counteracted totally by the retro-rocket $\mathrm{T}_{2}$ during the angle $\angle \mathrm{P}_{2} \mathrm{BP}_{3}$, which equals $\pi / 2-\theta$. Thus, the following equation is obtained:

$$
\frac{1}{2}\left[\mathrm{~J}_{\mathrm{c}}+\mathrm{m}\left(\mathrm{a}^{\prime 2}+\mathrm{b}^{2}\right)\right] \omega_{R 3}{ }^{2}=\mathrm{T}_{2} \mathrm{a}^{\prime}\left(\frac{\pi}{2}-\theta\right)
$$

Table 3. Meanings and values of the parameters

\begin{tabular}{ccc}
\hline Parameters & Meaning & Value \\
\hline $\mathrm{m}$ & total mass of $\left(\mathrm{m}_{1}+\mathrm{m}_{2}\right)$ & $100 \mathrm{~kg}$ \\
$\mathrm{~J}_{\mathrm{c}}$ & inertia of $\left(\mathrm{m}_{1}+\mathrm{m}_{2)}\right.$ & $12.7 \mathrm{~kg} \cdot \mathrm{m}^{2}$ \\
$\mathrm{a}^{\prime}$ & m abscissa length & $0.4635 \mathrm{~m}$ \\
$\mathrm{~b}$ & m ordinate length & $0.784 \mathrm{~m}$ \\
$\theta$ & landing slope angle & $30^{\circ}$ \\
$\beta$ & mechanical determined & $38^{\circ}$ \\
\hline
\end{tabular}

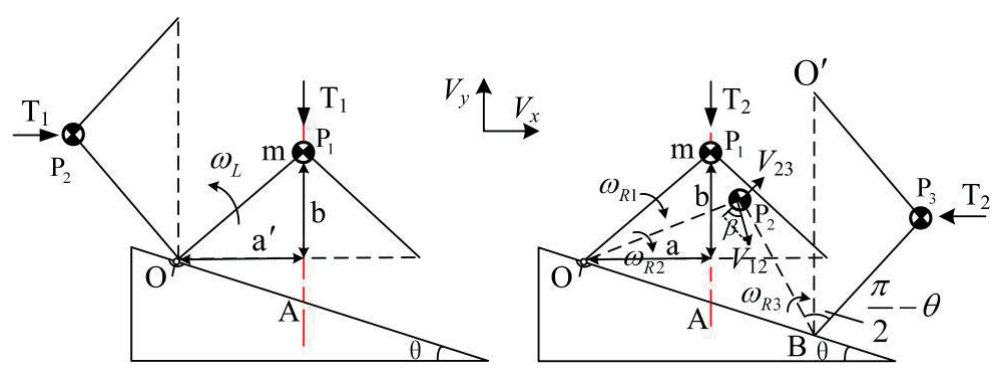

Fig. 3. Turning schematics of the landing mechanism 
Combining equations (13-18) yields the retro-rocket thrust $\mathrm{T}_{2}$ :

$$
\mathrm{T}_{2}=\frac{5194.5 e^{2}}{38.8-25.57 e^{2}}
$$

Substituting e with 0.6 , we obtain:

$$
\mathrm{T}_{2}=63.2 \mathrm{~N}
$$

The final retro-rocket thrust $\mathrm{T}$ should be no less than $\mathrm{T}_{1}$ or $\mathrm{T}_{2}$. In the paper, the retro-rocket thrust $\mathrm{T}$ is set to $65 \mathrm{~N}$.

\subsection{Estimation of the damping element damping $c_{1}$}

The dynamic model of the landing mechanism in the vertical direction could be simply expressed as Fig. 4 and equation (21), in which $\mathrm{k}$ is the stiffness of the landing mechanism.

$$
\left\{\begin{array}{l}
\mathrm{m}_{1} \ddot{x}_{1}-c_{1}\left(\dot{x}_{2}-\dot{x}_{1}\right)+k x_{1}=0 \\
\mathrm{~m}_{2} \ddot{x}_{2}+c_{1}\left(\dot{x}_{2}-\dot{x}_{1}\right)=0
\end{array}\right.
$$

The initial conditions of equation (21) can be written as follows:

$$
\left\{\begin{array}{l}
x_{1}(t=0)=0 \\
\dot{x}_{1}(t=0)=V_{y}=1.5 \\
x_{2}(t=0)=0 \\
\dot{x}_{2}(t=0)=V_{y}=1.5
\end{array}\right.
$$

The overloading accelerations of $\mathrm{m}_{2}$ are different, on account of different $c_{1}$. When the damping $c_{1}$ equals $900 \mathrm{Ns} / \mathrm{m}$, the numerical solution of the equation (21) is shown in Fig.

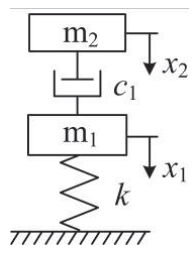

Fig. 4. Dynamic model in the vertical direction
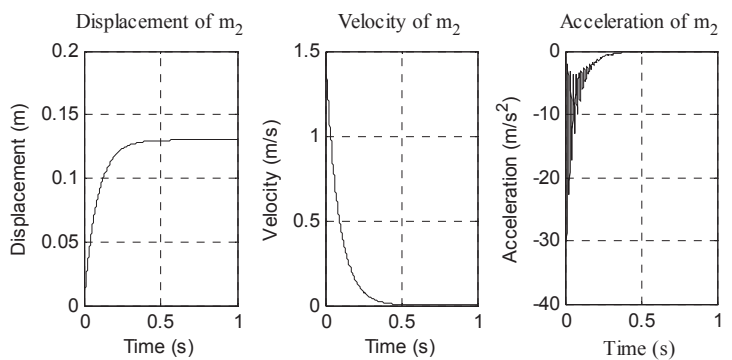

Fig. 5. Numerical solutions of the dynamic model
5. It can be found that the overloading acceleration of $\mathrm{m}_{2}$ is $30 \mathrm{~m} / \mathrm{s}^{2}$, and the stroke of the damping is $0.13 \mathrm{~m}$. These overloading acceleration and stroke are feasible for the landing mechanism. Thus, the parameters of the damping element are set to $c_{1}=900 \mathrm{Ns} / \mathrm{m}$ and $\mathrm{S}=0.13 \mathrm{~m}$, respectively.

\subsection{Calculation of cardan element damping $c_{2}$}

The $c_{2}$ is a rotational damping produced by two motors in the cardan element, and it is used to absorb the horizontal impact when landing. Therefore, the value of $c_{2}$ can be changed, by controlling the motors. The landing performance in changing $c_{2}$ that is varied depending on different initial landing velocities, will be better compared with that in constant $c_{2}$.

The value of $c_{2}$ can be calculated through the landing dynamic model shown in equations (3), (4), (5) with proper objective function and constraint conditions, after determining the values of $\mathrm{T}$ and $c_{1}$.

In the landing dynamic model, it can be found that during the turning, $c_{2}$ will influence the angular momentum of $m_{1}$. The smaller the angular momentum of $\mathrm{m}_{1}$, the harder the landing mechanism is to overturn. Thus, the smaller angular momentum of $\mathrm{m}_{1}$ is set to be the objective function to solve $c_{2}$. The constraint conditions to solve $c_{2}$ are: 1) the horizontal overloading acceleration of $\mathrm{m}_{2}$ is less than $10 \mathrm{~g}$; 2) the turning angle of $m_{2}$ relative to $m_{1}$ is less than $10^{\circ}$. The flow chart to calculate $c_{2}$ is shown in Fig. 6 .

The values of $c_{2}$ solved with different landing velocities are shown in Fig. 7. The data in Fig. 7 can be expressed as counter in Fig. 8. The landing mechanism will have a more stable landing when $c_{2}$ varies with $V_{x}$ and $V_{y}$ according to the

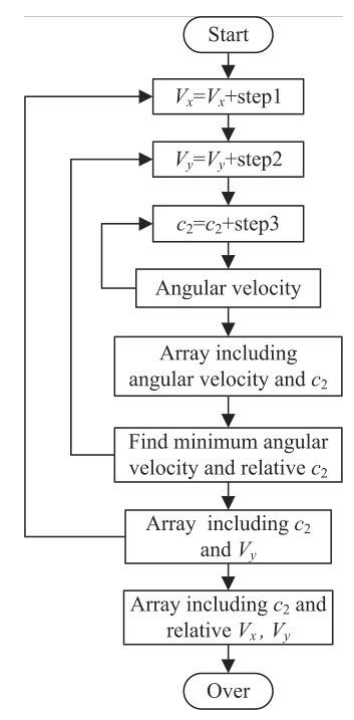

Fig. 6. Flow chart of calculating the parameter $c_{2}$ 
relationship shown in Fig. 7 or Fig. 8. The varying range of $c_{2}$ is between $17 \mathrm{Nm} \cdot \mathrm{s} / \mathrm{rad}$ and $111 \mathrm{Nm} \cdot \mathrm{s} / \mathrm{rad}$.

\section{Landing simulation}

The validities of the landing dynamic model and the parameters $\mathrm{T}, c_{1}, c_{2}$ need to be verified, by testing the landing performance. In the paper, the famous Adams software is used to simulate the landing performance. The landing mechanism has three classic landing modes, called 1-2 mode, 2-1 mode and 1-1-1 mode, respectively. Thus, the landing performances are tested in these three landing modes. The simulation parameters are shown in Table 4 .

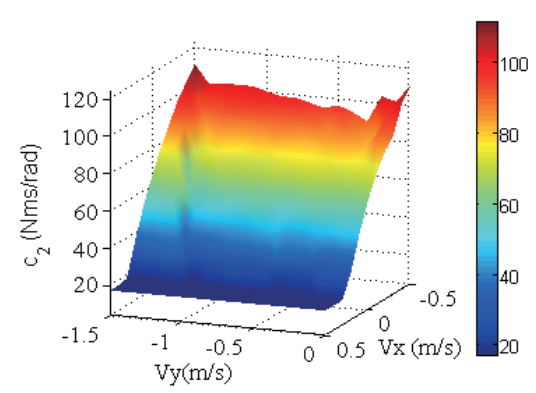

Fig. 7. Three-dimension surface of $c_{2}$ with different landing velocities

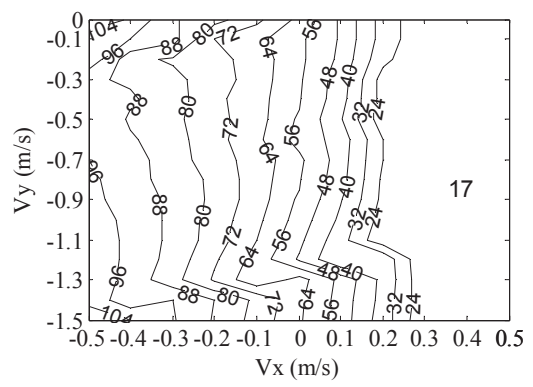

Fig. 8. Counter of $c_{2}$ with different landing velocities

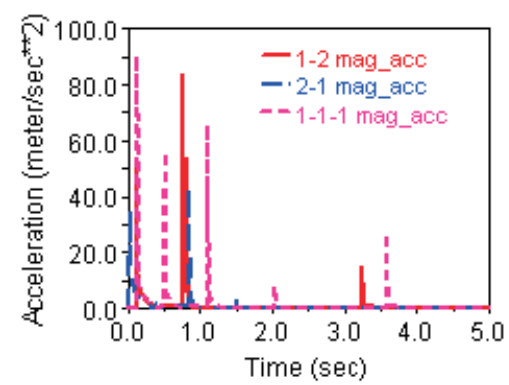

\subsection{Verification of the key parameters}

The landing performances in extreme landing conditions $\left(V_{x}=-0.5 \mathrm{~m} / \mathrm{s}, V_{y}=-1.5 \mathrm{~m} / \mathrm{s}\right)$ are tested with the estimated parameters $\mathrm{T}, c_{1}$ and $c_{2}$. The overloading acceleration of the equipment base reflects the damping performance, and the angular velocity of the landing legs reflects the stability time. Their values in the three classic landing modes are shown in Fig. 9. The left graph shows that the largest overloading accelerations of the equipment base are: about $80 \mathrm{~m} / \mathrm{s}^{2}$ in 1-2 mode; about $30 \mathrm{~m} / \mathrm{s}^{2}$ in $2-1$ mode, and about $90 \mathrm{~m} / \mathrm{s}^{2}$ in 1-1-1 mode. The right graph shows that the stability times are: about 3.6 second in 1-2 mode; about 1.5 second in $2-1$ mode and about 3.7 second in 1-1-1 mode. It can be found that the overloading accelerations are all less than $10 \mathrm{~g}$, and the landing stability times are all less than 4 second. Thus, the estimations of the parameters $\mathrm{T}, c_{1}$ and $c_{2}$ are valid.

\subsection{Influence of $c_{2}$ on the landing performance}

There are two modes of $c_{2}$ to select when landing: one is constant $c_{2}\left(c_{2}\right.$ remains constant at about $111 \mathrm{Nms} / \mathrm{rad}$ in all

Table 4. Simulation parameters

\begin{tabular}{cc}
\hline Parameters & Values \\
\hline Lander mass (lower) & $22 \mathrm{~kg}$ \\
Lander mass (upper) & $78 \mathrm{~kg}$ \\
Vertical velocity $V_{y}$ & $0 \sim 1.5 \mathrm{~m} / \mathrm{s}$ \\
Horizontal velocity $V_{x}$ & $-0.5 \sim 0.5 \mathrm{~m} / \mathrm{s}$ \\
Damping element damping & $900 \mathrm{Nm} / \mathrm{s}$ \\
Cardan element damping & $17 \sim 111(\mathrm{Nms} / \mathrm{rad})$ \\
Retro-rocket thrust & $65 \mathrm{~N}$ \\
Friction coefficient & 2.0 \\
Landing slope stiffness & $500000 \mathrm{~N} / \mathrm{m}$ \\
Asteroid gravity & $0 \mathrm{~g}$ \\
Landing mode & $1-2,2-1,1-1-1$ \\
Landing slope angle & $30^{\circ}$ \\
\hline
\end{tabular}

Fig. 9. Landing performance in the three classic landing modes Notes: Lines "mag_acc" represent the respective overloading accelerations of the equipment base. Lines "mag_ang_vel" represent the respective angular velocities of the landing legs. 
landing velocities), the other is optimal $c_{2}$ ( $c_{2}$ varies according to different initial landing velocities, as the rules shown in Fig. 7 or Fig. 8). Constant $c_{2}$ has the merits of easy control, whereas optimal $c_{2}$ can induce a better landing performance. The landing performances between the two modes of $c_{2}$ are compared in three classic landing modes, in the conditions that $V_{x}=0.1 \mathrm{~m} / \mathrm{s}$ and $V_{y}=-0.5 \mathrm{~m} / \mathrm{s}$, respectively. The optimal c2 in relation to $V_{x}=0.1 \mathrm{~m} / \mathrm{s}$ and $V_{y}=-0.5 \mathrm{~m} / \mathrm{s}$ is $55 \mathrm{Nms} / \mathrm{rad}$, which is shown in Fig. 7 and Fig. 8. The landing performance simulation results are shown in Fig. 10, Fig. 11 and Fig. 12, respectively, and the maximum overloading accelerations and stability times shown in these figures are summarized in Table 5. It can be found that both the maximum overloading accelerations and stability times with constant $c_{2}$ are all larger, than that with optimal $c_{2}$. Thus, optimal $c_{2}$ would lead to better landing performance.
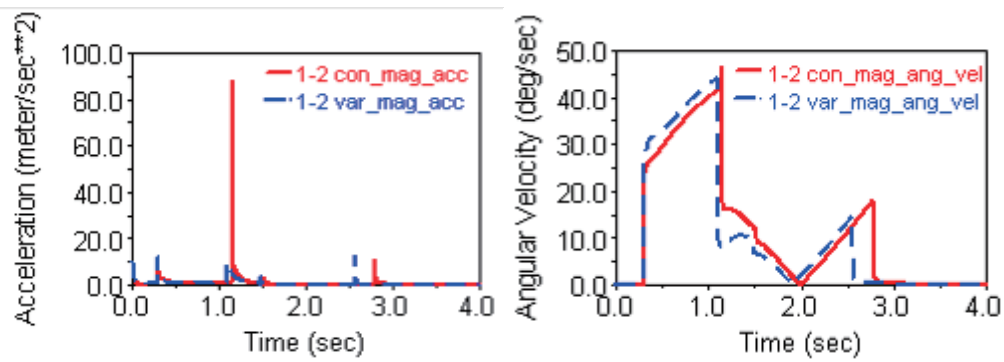

Fig. 10. Landing performance in 1-2 mode with different cardan element damping $c_{2}$

Notes: Real lines "1-2 con_mag_acc" and "1-2 con_mag_ang_vel" represent the overloading acceleration of the equipment base, and angular velocity of the landing legs, respectively, with constant $c_{2}$ in 1-2 landing mode. Dashed lines "1-2 var_mag_acc" and "1-2 var_mag_ ang_vel" represent the overloading acceleration of the equipment base, and angular velocity of the landing legs, respectively, with optimal $c_{2}$ in 1-2 landing mode.
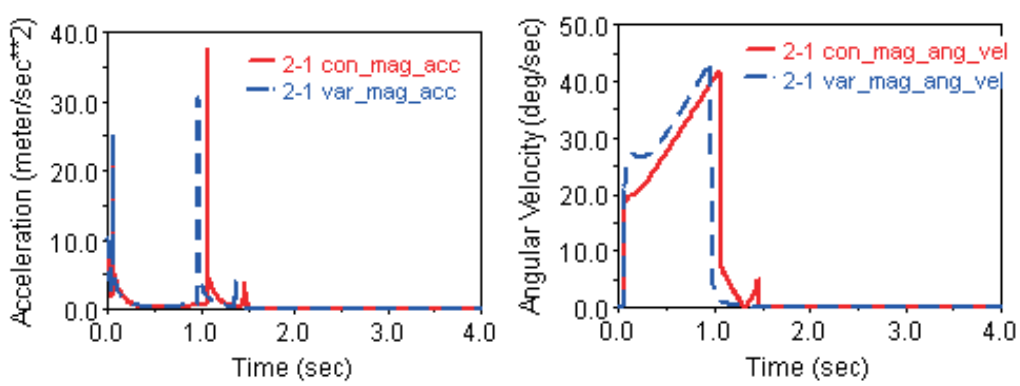

Fig. 11. Landing performance in 2-1 mode with different cardan element damping $c_{2}$

Notes: Real lines "2-1 con_mag_acc" and "2-1 con_mag_ang_vel" represent the overloading acceleration of the equipment base, and angular velocity of the landing legs, respectively, with constant $c_{2}$ in 2-1 landing mode. Dashed lines "1-2 var_mag_acc" and "1-2 var_mag_ ang_vel" represent the overloading acceleration of the equipment base, and angular velocity of the landing legs, respectively, with optimal $c_{2}$ in 2-1 landing mode.
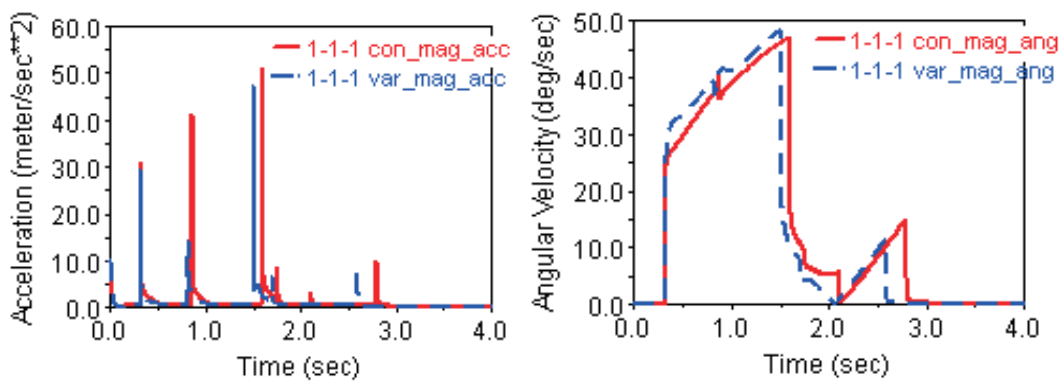

Fig. 12. Landing performance in 1-1-1 mode with different cardan element damping $c_{2}$

Notes: Real lines "1-1-1 con_mag_acc" and "1-1-1 con_mag_ang" represent the overloading acceleration of the equipment base, and angular velocity of the landing legs, respectively, with constant $c_{2}$ in 1-1-1 landing mode. Dashed Lines "1-1-1 var_mag_acc" and "1-1-1 var_mag_ang" represent the overloading acceleration of the equipment base, and angular velocity of the landing legs, respectively, with optimal $c_{2}$ in 1-1-1 landing mode. 


\section{Conclusions}

A landing mechanism for asteroid with soft surface is presented. Reasonable values of the three key parameters (retro-rocket thrust $\mathrm{T}$, damping element damping $c_{1}$ and cardan element $c_{2}$ ) that influence the landing performance of the landing mechanism presented in the paper are: $\mathrm{T}=65 \mathrm{~N} ; c_{1}=900 \mathrm{Ns} / \mathrm{m}$; and $c_{2}$ changes between $17 \mathrm{Nms} / \mathrm{rad}$ and $111 \mathrm{Nms} / \mathrm{rad}$, in relation to the initial landing velocities. The overloading accelerations of the equipment base are less than $10 \mathrm{~g}$, and the stability times are less than $5 \mathrm{~s}$, when landing with the estimated values of $\mathrm{T}, c_{1}$, and $c_{2}$. Furthermore, optimal $c_{2}$ in relation to the landing velocities will lead to a good landing performance, with comparison to constant $c_{2}$. The simulation results show that the landing dynamic model, and the methods to estimate key parameters, are reasonable. The estimations of key parameters can be used to guide the design of the landing mechanism.

In future, the landing mechanism will be manufactured, and then the validities of the landing mechanism and its parameters will be tested physically, under microgravity.

\section{Acknowledgement}

This work was financially supported by the National High Technology Research and Development Program of China (863 Program) (No. 2008AA12A214), the National Natural Science Foundation of China (No. 51105091), and the National Program on Key Research (No. 2013CB733103).

\section{References}

[1] Morrison, D., "Asteroid and comet impacts the ultimate environmental catastrophe", Philosophical Transactions of the Royal Society. Vol. 364, No. 1845, 2006, pp. 2041-2054.

[2] Bland, P. A., and Artemieva, N. A., "The rate of small impacts on earth", Meteoritics and Planetary Science, Vol. 41, No. 4, 2006, pp. 607-631.
[3] Blessing, M., Quintana, E., Persaud, R., Jeffress, S., "Asteroids working group report" Proceedings of the Next Generation Exploration Conference, Washington, DC, USA, 2006.

[4] Ross, S. D., "Near-earth asteroid mining", Space Industry Report, 2001, pp. 1-24.

[5] Lavendaer, R. E., "Equations for two-dimensional analysis of touch-down dynamics of spacecraft with hinged legs including elastic, damping, and crushing effects", George C. Marshall Space Flight Center, MTP-AERO-63-76, 1963, pp. $1-43$.

[6] Irwin, D. C., "Landing dynamics study for lunar landing research vehicle”, National Aeronautics and Space Administration, NASA CR-428, 1965, pp. 1-73.

[7] Admire, J., and Mackey, A., "Dynamic analysis of a multi-legged lunar landing vehicle to determine structural loads during touchdown", National Aeronautics and Space Administration, NASA TN-D 2582, 1965, 1-36.

[8] Herr, R. W., Leonard, H. W., "Dynamic model investigation of touchdown stability of lunar-landing vehicles", National Aeronautics and Space Administration, NASA TN D-4215, 1967, pp. 1-25.

[9] Wang, S. C., Deng, Z. Q., Hu, M, Gao, H. B., "Dynamic model building and simulation for mechanical main body of lunar lander", Journal of Central South University, Vol. 12, No.3, 2005, pp. 329-334.

[10] McLean, C. H., Riesco, M. E., Gravseth, I. J., Dissly, R. W., "Design of a robotic lunar lander for lunar south pole exploration", Proceedings of the AIAA Space 2008 Conference and Exposition, California, USA, 2008.

[11] Walton, W.C., Herr, R. W., and Leonard, H. W., "Studies of touchdown stability for lunar landing vehicles", Journal of Spacecraft and Rockets, Vol.1, No.5, 1964, pp. 552-556.

[12] Bibring, J.P., Rosenbauer, H., Boehnhardt, H., "The rosetta lander ("PHILAE") investigations", Space Science Reviews, Vol. 128, No. 1-4, 2007, pp. 205-220.

[13] Biele, J., Ulamec, S., "Capabilities of philae, the rosetta lander", Space Science Reviews, Vol. 138, No. 1-4, 2008, pp. 275-289.

[14] Yano, H., Kubota, T., Miyamoto, H., et al, “Touchdown

Table 5. Landing performances with constant and optimal $c_{2}$ in three landing modes

\begin{tabular}{ccccc}
\hline & & 1-2 landing mode & 2-1 landing mode & 1-1-1 landing mode \\
\hline $\begin{array}{c}\text { Maximum } \\
\text { overloading } \\
\text { acceleration }\end{array}$ & ${\text { Constant } \mathrm{c}_{2}}_{\text {Optimal } \mathrm{c}_{2}}$ & $90 \mathrm{~m} / \mathrm{s}^{2}$ & $38 \mathrm{~m} / \mathrm{s}^{2}$ & $52 \mathrm{~m} / \mathrm{s}^{2}$ \\
$\begin{array}{c}\text { Stability } \\
\text { time }\end{array}$ & $18 \mathrm{~m} / \mathrm{s}^{2}$ & $30 \mathrm{~m} / \mathrm{s}^{2}$ & $48 \mathrm{~m} / \mathrm{s}^{2}$ \\
Constant $\mathrm{c}_{2}$ & $2.8 \mathrm{~s}$ & $1.5 \mathrm{~s}$ & $2.8 \mathrm{~s}$ \\
\hline
\end{tabular}


of the hayabusa spacecraft at the muses sea on itokawa", Science, Vol. 312, No. 5778, 2006, pp. 1350-1353.

[15] Erik, A., "Adventures in near-earth object exploration", Science, Vol. 312, No. 5778, 2006, pp. 1328-1329.

[16] Muirhead, B., Kerridge, S., "The deep space 4/ champollion mission", Proceedings of the 3rd IAA International Conference on Low Cost Planetary Missions, California, USA, 1998.

[17] Hilchenbach, M., Kuechemann, O., Rosenbauer, H., "Impact on a comet: rosetta lander simulations", Planetary and Space Science, Vol. 48, No. 5, 2000, pp. 361-369.

[18] Lupishko, D. F., Martino, M. D., "Physical properties of near-earth asteroids", Planetary and Space Science, Vol. 46, No.1, 1998, pp. 47-74.

[19] Yeomans, D., "Small bodies of the solar system",
Nature, Vol. 404, No. 6780, 2000, pp. 829-832.

[20] Ulamec, S., Biele, J., "Surface elements and landing strategies for small bodies missions-philae and beyond", Advance in Space Science, Vol. 44, No. 7, 2009, pp. 847-858.

[21] Thiel, M., Stöcker, J., Rohe, C., et al, “The rosetta lander anchoring system", Proceedings of the 10th European Space Mechanisms and Tribology Symposium, San Sebastián, Spain, 24-26 September 2003, pp. 239-246.

[22] Ghavimi, A. R., Serricchio, F., Hadaegh, F.Y., et al, "Autonomous landing and smart anchoring for insitu exploration of small bodies", Artificial Intelligence, Robotics and Automation in Space, Proceedings of the Fifth International Symposium, ESTEC, Noordwijk, the Netherlands, 1999. 